\title{
Use of Modern Contraceptive Methods in Burkina Faso: What are the Obstacles to Male Involvement in Improving Indicators in the Centre-East and Centre-North Regions?
}

This article was published in the following Dove Press journal:

Open Access Journal of Contraception

\author{
Aristide Romaric Bado (ID) ${ }^{1,2}$ \\ Hermann Badolo ${ }^{3,4}$ \\ Lamoussa Robert Zoma ${ }^{5}$ \\ 'Institute for Research in Health Sciences \\ (IRSS), Biomedical and Public Health \\ Department, Ouagadougou, Burkina \\ Faso; ${ }^{2}$ West African Health Organisation \\ (WAHO), Demography and Sexual and \\ Reproductive Health Project, Bobo- \\ Dioulasso, Burkina Faso; ${ }^{3}$ Institut National \\ de Santé Publique (INSP)/Centre MURAZ, \\ Bobo-Dioulasso, Burkina Faso; ${ }^{4}$ University \\ of the Western Cape, Cape Town, South \\ Africa; ${ }^{5}$ Davycas International, \\ Ouagadougou, Burkina Faso
}

Introduction: In Burkina Faso, despite several efforts to improve contraceptive uptake, contraceptive prevalence remains low. Studies suggest that the low levels of family planning (FP) practices can be partially attributed to the low participation of men in reproductive health programmes. Involving men in FP programmes in Burkina Faso is thus imperative, but the obstacles to this are poorly documented. This study has two objectives to explore the perspectives of men and women on barriers to contraceptive use and to identify the strategies to increase male involvement in family planning.

Methods: It is a qualitative study using 20 focus groups and 52 in-depth individual interviews in two regions (North Central Region and Central East Region) with a sample of 29 adult men and 23 women who were married and had children or not. Interviews were conducted in Moore (the national language commonly spoken in both regions). All interviews were recorded and transcribed into French using Microsoft Word. Then, content analysis was carried out using the constant comparison method to identify the major themes. Results: The results show that men's attitudes are still a significant barrier to women's use of modern contraceptives. The reasons women do not use contraception and men do not adhere to FP programmes include lack of method knowledge, negative beliefs and perceptions about modern contraceptive methods, and the side effects of contraceptives. Cultural norms and preferences for large families are also common barriers to FP. However, the results showed that men's awareness of FP, communication between spouses, and access to FP services can promote men's adherence to FP programmes in the Centre-East and CentreNorth regions of Burkina Faso.

Conclusion: Efforts should be made to improve educational standards, especially for men, and reorient FP services to make them more accessible to men.

Keywords: involvement of men, family planning, barriers, contraceptive use, Burkina Faso

\section{Background}

Family Planning (FP) programmes are an essential component in reducing maternal and child mortality rates, as they enable women to delay, space, or limit their pregnancies. They involve a conscious decision about family size and child spacing. ${ }^{1}$ In sub-Saharan Africa (SSA), despite the benefits of FP, indicators of fertility, desire for family size, and the use of modern contraceptive methods are among the lowest in the world, indicating a very high unmet need.
Correspondence: Aristide Romaric Bado Institute for Research in Health Sciences (IRSS), Biomedical and Public Health Department, 03 BP 7192 Ouagadougou 03, Burkina Faso

Email arbado@gmail.com
Open Access Journal of Contraception 2020: I I |47-I56 
Fertility trends show that SSA is experiencing an extremely slow decline in fertility compared to the other regions of the world. Fertility remains high in countries where access to FP services is low; the average number of children per woman is more than 7 in Niger and about 6 in Burkina Faso. The prevalence of contraceptive use is low - below 30\% in Burkina Faso - to accelerate the demographic transition.

The persistence of high fertility has been the subject of extensive research over the past decade. Researchers have suggested various reasons for the acceptance and use of modern FP methods remaining low despite the high fertility. These include low accessibility of services, low status of women, high illiteracy rates among women, the patriarchal nature of society, and general lack of male involvement in FP. ${ }^{2}$ In patriarchal societies such as Burkina Faso, men are often the main decision makers regarding family size and FP. Their approval is crucial to their wives' choice, timing, and use of contraceptive methods.

The importance of the human role in the use of FP has been recognised by the international community and was reaffirmed at the 1994 International Conference on Population and Development (ICPD) in Cairo. ${ }^{3}$ The 1995 World Women's Conference in Beijing also reinforced this message by recognising the importance of "the shared responsibility of men and women in all matters related to reproductive health". Both men and women should be concerned about FP programmes. ${ }^{1}$ Numerous studies have documented the benefits of men's involvement in maternal health in developing countries, including improved access to antenatal and postnatal services for mothers and increased likelihood of contraceptive use. ${ }^{4-6}$

However, men's involvement in FP was not apparent for a long time. This is because in recent decades, FP programmes have been biased, nearly excluding men simply because most services were offered in maternal and child health centres. ${ }^{7,8}$ Most research studies and information campaigns have focused on women, reinforcing the belief that FP is largely a women's issue, with men playing a peripheral role. However, despite the growing awareness of the importance of men's involvement, men are still not very visible in FP programmes. There are various factors that influence men's involvement in FP. In Burkina Faso, the low level of FP practices is largely attributable to the low involvement of men in reproductive health programmes. ${ }^{9}$ Andro ${ }^{10}$ found in his study that in West African countries, only a minority of the married men interviewed - ranging from $23 \%$ in Niger and Senegal to
$43 \%$ in Mali - reported discussing FP with their wives in the last 12 months. In Burkina Faso, the results of various studies showed that the proportion of men who discuss FP with women is very low (35.7\% in the 2003 Demographic and Health Survey [DHS]), and a study in Burkina Faso by Congo Z. ${ }^{11}$ showed that if a woman communicates with her husband and receives a favourable reaction, she is 4.64 and 3.82 times more likely, respectively, to use modern contraceptives. Involving men in the FP programmes in Burkina Faso is therefore imperative and the following questions become relevant: how can this be done and what are the barriers to their involvement?

Past studies have identified cultural norms and values, religious beliefs, socio-economic factors, and psychological factors as barriers to men's participation in FP. ${ }^{8,12-14}$ Moreover, the predominant focus of FP programmes on women has caused men to be unconcerned about FP. In addition, the feminine orientation of FP programmes does not recognise the dominant role men play in making decisions regarding reproductive health.

Men in developing countries are key decision makers, determining women's access to maternal health services and influencing their health outcomes. ${ }^{6}$ Schuler et $\mathrm{al}^{15}$ (1995) found that women in Bangladesh depend on their husbands' decisions about FP and reproductive health. Sometimes, husbands do not allow their wives to use contraceptives, and any decision contrary to their husbands' is punished with repudiation and verbal and/or physical abuse.

Gender norms - the rules and expectations that shape and regulate the appropriate behaviour of men and women in society - greatly influence sexual and reproductive health. In adulthood, men's voices often carry more weight than women's in family decisions, such as when to start a family and how many children to have. This imbalance translates into unequal communication among couples about conception and contraception. Investments in FP programmes often fail to achieve the desired results because they do not address issues such as women's subordinate social statuses, their economic dependence on men, their limited power in decision-making, the power dynamics within the household, and other harmful patriarchal norms.

Men's involvement in decisions about contraception, sex, and childrearing strongly influences sexual and contraceptive behaviour, greatly enhances or reduces discord in relationships, and reinforces their responsibility for the children they father. ${ }^{16}$ Without the active participation of 
husbands in FP activities, the goal of improving women's reproductive health becomes difficult to achieve. Given these women's inability to use contraceptives without their husbands' permission, the conditional approval of contraception by men can be a serious hurdle in the acceptance and use of contraceptives. ${ }^{3}$

This study has two objectives: (a) to explore the perspectives of men and women on barriers to contraceptive use, and (b) to identify the strategies to increase male involvement in family planning.

\section{Method}

\section{Context of the Study}

Burkina Faso, a West African country, is one of the poorest in the world. Burkina Faso's population was estimated at $20,870,060$ in 2019 according to projections by the National Institute of Statistics and Demography (INSD). It is composed of $51.7 \%$ women and is mostly young (46.6\% of the population is under 15 years old). Burkina Faso is a high fertility country with an average of 5.1 children per woman. According to the results of the 2010 DHS, the median age of women at first union is estimated at 17.8 years and is almost identical to the age at first sexual intercourse (17.8 years).

Burkina Faso's Human Development Index (HDI) for 2018 stands at 0.434 , placing the country in the low human development category. Further, according to the Human Development Report of 2019, it ranks 182nd among 189 countries and territories. Burkina Faso has long been characterised by its high population growth, with a total fertility rate that has changed very little despite the FP policies in place since the $1980 \mathrm{~s}$. The average number of children per woman rose from 6.1 in 1960 to 6.9 in 1993 and then decreased to 6.0 in 2010 and 5.4 in 2015. Between 1993 and 2015, the average number of children per woman decreased by $1.5 .{ }^{17}$ The modern contraceptive prevalence rate, which remains low, rose from $12 \%$ in 1998 to $14 \%$ in 2003 and $16 \%$ in $2010 .{ }^{18-21}$ The modern contraceptive prevalence rate was $30.1 \%$ in 2018, according to the results of Performance Monitoring and Accountability 2020 (PMA 2020). ${ }^{22}$ The low modern contraceptive use rate in Burkina Faso conceals regional disparities that reflect an equity problem in terms of FP coverage.

The Centre-North and Centre-East regions, the subject of this study, are regions with low levels of FP indicators at the national level. According to the results of the 2010 DHS, the rate of use of modern contraceptive methods was $9.3 \%$ for married women in the Centre-North region and $9 \%$ in the Centre-East region; these rates were below the national average of $16 \%$ (DHS, 2010). This study covered the Kaya health district in the Centre-North region and the Ouargaye health district in the Centre-East region, which differ from the other districts in terms of their FP indicators. A mixed methods study (quantitative and qualitative) was undertaken. The results of this article refer to those of the qualitative survey.

\section{Sample}

It is a qualitative study using 20 focus groups and 52 indepth individual interviews in two regions (North Central Region and Central East Region) with a sample of 29 adult men and 23 women who were married and had children. The respondents were aged 21 years or older.

Informants for the individual in-depth interviews were selected among married men and women, men and women opinion leaders (village/local leaders, religious leader, traditional practitioner, heads of associations, etc.). For the focus groups, the following profiles are concerned: men in union aged 15 years or older (young/old) and women in union aged 15 years or older (young/old). ${ }^{21}$ The purpose of the study was to investigate in depth the reasons for and barriers to the use of FP services and to identify actions to be taken to involve men in the promotion and use of FP services. The sampling was reasoned. The interviews were conducted in villages located in the Kaya and Ouargaye health districts.

\section{Data Collection}

Two qualitative interview guides were used: individual interviews and focus groups. These semi-structured interview guides were built from the literature and real-life experience on cultural, religious and contextual barriers to contraceptive use and on how to involve men to improve FP. The surveys in both regions were conducted by fifteen (15) interviewers with a master's degree in sociology with extensive experience in conducting qualitative surveys. The interviewers were accompanied and supervised in the field by three study investigators. The interviewers were trained for 3 days on the collection tools and the methodology of the study. Interviews were conducted in Moore (the national language commonly spoken in both regions). All interviews were recorded and transcribed into French using Microsoft Word.

\section{Data Analysis}

The interviews were transcribed and translated into French as necessary. The transcripts were subject to content 
analysis using constant comparative technique ${ }^{23}$ to identify the major themes according to the themes covered in the interview guides. No software was used. The study investigators first read all the interviews to identify the different themes, and each interview was then analysed according to the themes identified in the first round of reading. The results were triangulated by the investigators. Data were coded using a set of predefined codes based on the discussion guide as well as emerging themes. The thematic coding framework was then used to evaluate all interview transcripts.

The analysis looked for patterns and associations regarding emerging themes, focusing on factors and barriers to men's involvement in FP from the perspectives of men, women, and opinion leaders. This document contains nonidentifiable information about study participants and uses their quotes to characterise emerging issues and themes.

\section{Ethical Considerations}

This study was approved by the National Health Ethics Committee of Burkina Faso. Moreover, permissions were obtained from the health districts of Kaya and Ouargaye prior to collecting data from households. The participants gave their verbal consent and decided to participate in the study voluntarily. Verbal informed consent form was approved by the National Health Ethics Committee of Burkina Faso, and participants under the age of legal majority could provide informed consent on their own behalf. All participants were informed about the purpose of the study, in accordance with the Declaration of Helsinki, and that they also consented to publication of anonymized responses and quotes. No information identifying them was linked to the interviews or retained after the analysis ended. They were guaranteed confidentiality regarding the information collected.

\section{Results}

The data analysis led to the identification of two themes: barriers to contraceptive use and male involvement. The theme of barriers to FP has several sub-themes and is analysed from the perspectives of both men and women. The theme of male involvement consists of three subthemes: men's awareness of FP, communication between spouses, and men's access to FP services.

\section{Barriers to FP}

Although enormous efforts have been made to increase adherence to and the use of FP in Burkina Faso, barriers still exist. The actual level of FP is still low at the national level and especially low in the Centre-North and CentreEast regions. The results show that there are several types of barriers to FP: cultural acceptability, traditional beliefs, ignorance about contraceptive security, lack of community support, and misinformation and rumours.

\section{Lack of Knowledge is the Main Reason}

Lack of knowledge about FP, especially modern contraceptive methods, seems to be a major cause for their low usage. The results of our study show this to be true for both men and women. A 47-year-old woman in Nessmetenga, whose husband was not in favour of FP, justified the husband's attitude by saying,

"He knew a lot of things he didn't know about the importance of family planning". A speaker at a women's focus group in Nessmetenga said the following:

The men are ignorant, they don't have information so they prevent their wives from doing family planning, but since it is the women who suffer and who give birth, they can go in secret to do the planning. Some women even leave their cards with the health worker so that their husbands don't see it.

The comments at a focus group for men in Mané reinforced the idea that the lack of information on FP is one of the primary reasons why men do not practise it:

I think that those who refuse to let their wives do family planning are ignorant $(\ldots)$ otherwise most people think that contraceptives can lead a woman to stop having children $(\ldots)$

\section{Negative Beliefs and Perceptions About Modern Contraception}

Analyses of the interview data indicate that negative beliefs and perceptions about modern contraception persist among both men and women in the study areas. Certain preconceptions still present in the populations there are not favourable to modern contraceptive practice. In fact, infertility and morbidity in women is associated with the practice of FP. The following comment, spoken at a focus group in Kaya, illustrates some of the misconceptions and misperceptions that people have about FP:

In fact, there was information circulating that contraceptives were there to stop women giving birth for good and it was a group of people who were circulating this information, which meant that people no longer wanted to adhere to family planning. 
For women, the use of contraceptive methods can have disadvantages, with side effects being a major concern. The pill often causes headaches and weight gain and is believed to cause cancer. The injections cause amenorrhea, which is feared by the community because it is interpreted as an accumulation of impure blood in the body that will eventually lead to disease or infertility. One respondent, from the focus group of women in Raguitenga, described the side effects of injections as, "I don't see my period but I'm not sick, it doesn't bother me". Moreover, the women in the focus group in Piboaré confided the following:

Many people say that contraception has side effects on health, others say that if you put Norplant on you can't have children or that Norplant can sink into your body, others say that if you take the pills it makes you nauseous, so sometimes women get discouraged.

False beliefs and perceptions about FP, especially modern contraceptive methods, are one of the reasons men refuse to let their wives use them. When asked about men's refusal to allow their wives to use contraception, a religious leader in Kaya said the following:

Some men say that if you practise contraception for 2 or 3 years without stopping, you will want to have a child, but you won't be able to anymore, that's why some men scold their wives so that they don't leave to practise contraception.

Some men believe that the use of modern contraceptive methods can lead women to marital infidelity, hence their rejection of FP. A religious leader in Pibaoré stated that, "And other men refuse to let their wives place the Norplant, for example, otherwise it will bring her out". At the focus group of women in Raguitenga, the following was said:

Some men refuse to let their wives do family planning because they think that if the woman does family planning, you will be free to engage in depravity, but you, the woman who suffers in the house, you have to hide if you don't have permission to go and do family planning so that you can rest a little before starting again.

\section{Religious Beliefs and FP}

Birth spacing is not forbidden by religion, as reported to us by Muslim, Christian, and traditional religious leaders. One catechist said the following:

The Catholic religion does not prohibit the spacing of children's births, it is to allow children to develop in the home and to be able to take charge of their schooling, but the religion does not encourage contraception, but it does encourage the spacing of births in a natural way.

Similarly, an imam claims that, "The adoption of contraception is not prohibited in religion". However, it should be recognised that religious leaders, especially those of the Catholic faith, do not support the use of modern contraceptive methods but rather the use of natural contraception. Some religious leaders believe that the use of modern contraceptive methods is unnatural, as evidenced by the following statements.

The abbot of Ouargaye: The point of view of the church is very clear: the church promises family planning but the natural method that is recommended, the church does not admit contraceptives for example, the IUD and other, anything that goes against the nature of man.

\section{A Muslim leader in Kaya:}

For the Islamists, they are against contraception, they say that you have to give birth to many children because each child comes with its chance. So, if you give birth to just one child, it can be difficult, but if you give birth to many children, one of those children can have the means to take care of you one day. So, a lot of Islamists don't want to. It's not the younger Islamists but the older ones when they notice that a woman has been more than two years without getting pregnant, they will start to search and if they are convinced that the woman is doing something, they will tell her to stop. For them, every child comes with its chance.

Other religious leaders, on the other hand, accept and even defend using modern contraceptive methods to space pregnancies. However, none of them justify FP for economic reasons, as shown by the following quotes.

The imam of Korsimoro, Kaya: The Koran does not say that family planning is forbidden in the religion, it does not say that in the religion, we talk about it.

The pastor of Korsimoro, Kaya: The adoption of contraception to space the birth is not forbidden in our religion, it is true that in the Bible, there is a passage that says that we must multiply and fill the earth, but now we must give birth to few children and if we see that couples have close births, we approach them to tell them to space the births, but in the Bible, it is not forbidden to practise contraception.

The imam of Pibaoré, Kaya:

The adoption of contraception is not forbidden in religion but now we are the ones who are going to forbid it. You 
see that there are many people and they don't have long lives. There is no more rain in abundance and then religion forbids to take the woman. But if you have the means, you can marry several women. But if you don't have the means, you must marry one woman. If you really have nothing, you cannot marry a woman but every month, you must fast so that you don't want a woman.

\section{Women's Perspectives on Barriers to FP Refusal of Men and Covert Contraceptive Use}

The transcripts draw attention to the practice of women using contraceptives without informing their husbands. A woman may use a contraceptive in secret since men are a significant barrier to FP practices. This is true in Kaya and Ouargaye as well. Several participants did not cite reasons for the men's refusal to allow their wives to use contraception. However, it seems that rumours are the primary reason. Even if it is not possible to assess the frequency of such a phenomenon from a qualitative study, it can nevertheless be said that such a phenomenon is not exceptional. Many women castigate men's reluctance to use modern contraception, as evidenced by the following statements.

Women in the focus group in Kaya: In any case, there is a large proportion of men who refuse to allow their wives to do family planning.

A woman in Ouargaye: Sometimes among us, we hear some women say that their husbands do not accept that they do this or that, but we have never heard that a woman went to do family planning and then there was a fight between her and her husband.

A woman in Kaya: But because women now have information on 100 women, there are more than 50 women practicing family planning in secret. There are men who know that their wives are practicing family planning, but others don't know and then because of that you can leave your home...

Women in the focus group in Ouargaye: Some men refuse to let their wives do family planning because they think that if the woman does family planning, you will be free to engage in depravity, but you, the woman who suffers in the house, you have to hide if you don't have permission to go and do family planning so that you can rest a little before starting again.

\section{Side Effects of Methods and Rumours}

Side effects and rumours are important barriers to contraceptive use. The transcripts suggest that if all methods were free of side effects, contraceptive prevalence would be much higher than it is now. Recriminations against modern contraceptive methods, especially injectables, are prolific among both women who use them and those who do not. All groups reported hearing about or experiencing side effects, which included the following:

A woman in Kaya: People everywhere are saying things like, for example, that health workers want to flatter women and then get them to stop having children, or that there are side effects or that my wife can't have children anymore. But because women need it, they hide to take it, and even if you bring it home and you don't hide it well, no one will know, so it really helps women to be able to thrive in their homes.

Women in the focus group in Kaya: If I take the pills, I feel nauseous, which I can't stand, but there is a solution, if I take it, I don't mind; I take the injection. When I do the injection, I don't see my period, but I'm not sick, it doesn't bother me.

Women in the focus group in Ouargaye: I told you earlier that when I take the pills, I feel nauseated because I know that my body reacts differently, but some women don't know that it's not the same thing. If they leave and then they have discomfort, they start talking to everyone at the moment. The one who is listening and who wanted to go, for example, the next day will not go anymore, so right now it's fear. Those who haven't done family planning don't want to do it because they don't know that contraceptives don't work the same for everyone.

\section{Men's Perspectives on Barriers to FP Many Children as Social Insurance}

For some of the men interviewed, their desire to have many children is the main reason for not using contraceptive methods. For them, many children are a sign of social prestige. The following words, from a man in Kaya, sum up this idea well:

In fact, what leads us to refuse contraceptives is that we wanted a lot of children. Our parents used to say that the one who has a lot of people is considered a leader. And if you had people, everything you wanted to do as a job is very fast ...

\section{Infidelity of Women}

The interviews suggest that for most of the men interviewed, both in individual interviews and in focus groups, the possibility of infidelity is a fundamental reason behind 
their refusal to use modern contraceptive methods. For men, when a woman is on a contraceptive, she no longer runs the risk of becoming pregnant and can easily cheat on her husband without fear. The following statements reflect this view.

A man in Ouargaye: Here in the village, some men think that contraceptive methods are a source of infidelity, so we have to get it out of their heads. For them, infidelity is when a woman gets pregnant by another man who is not her husband. So, first there is the cultural weight, the cultural burdens, so we'll have to try to lift all that.

A man in Kaya: We believe that women will take advantage of family planning to do stupid things ...

Men in the focus group in Ouargaye: There are men who think that if a woman does family planning, she will not be able to have children, or she will go into perversion so they don't want to let their wives do the planning.

A man in Kaya: In fact, for example, the men who are at the sites if their wives happen to have had FP and if they go out with other men, for example, this gentleman who is at the site and the in-laws will say that, as her husband is not around, they won't do anything to disappoint her and make her leave so she goes out every night, but if she is not on contraception if she gets pregnant, her husband will repudiate her so she's quiet at the moment ...

\section{Involvement of Men in FP Programmes Outreach as a Means of Informing Men About FP}

Involving men in FP programmes is necessary to increase contraceptive use among women and thus promote birth spacing. The results of our study show that men's involvement in FP programmes can be achieved by raising awareness. In the words of one religious' leader, what should be done

is to continue to educate them so that they understand the importance of contraception. Otherwise, if you don't know the advantages of a thing, it is very difficult to be able to adhere to it.

This can be done at markets, at religious ceremonies, and through radio broadcasts.

\section{Spousal Communication Could Encourage Men's Participation in FP Programmes}

The results of this study show that many women make the decision, sometimes with the complicity of health workers, to use a contraceptive method without warning their spouse on the pretext that they would refuse. A midwife in the Kaya health district said the following:

Some women sneak in and do [FP] on the sly. They don't want their husbands to know, so they come at hours when they go downstairs, for example at 1 p.m., or they come directly to [the midwife's] house so that their husbands don't know.

Health workers are often complicit in these behaviours. One says, "I'm in complicity with women because in FP, there are men who are really complicated". Such attitudes are not conducive to discussion between spouses, and the wife would lack her husband's support while suffering from the side effects of medication. It is therefore necessary to make couples aware of the need to decide on contraception together. Literature shows that a partner who is in favour of FP is four times more likely to allow their wife to use modern contraception. Discussion of FP among couples thus seems to be one of the most relevant determinants of modern contraceptive practice.

\section{Opening FP Services to Men}

In Burkina Faso, FP programmes are generally more concerned with women, particularly married women. Men feel excluded, which leads to their disinterest and lack of involvement in FP programmes. Opening FP services to men would help educate them on FP and also motivate them to assist their wives in choosing the modern contraceptive method most suited to them. A woman in Nessemtenga states that, "[men] have no information so they prevent their wives from doing family planning".

\section{Discussion}

This study aimed to examine barriers to men's involvement in FP programmes in two regions of Burkina Faso. The results of the study showed that several factors explain why women do not use FP and also identified various avenues for men's involvement in FP programmes.

The reasons for which women do not use contraception and men do not adhere to FP programmes include lack of method knowledge, negative beliefs and perceptions about modern contraceptive methods, and the side effects of contraceptives. Cultural norms and the preference for a large family are also regularly cited barriers to practising FP. Regarding men's involvement, the results showed that increasing men's awareness about FP, communication between spouses, and men's access to FP services can promote men's adherence to FP programmes in the Centre- 
East and Centre-North regions of Burkina Faso. These results are consistent with those of other studies conducted in Africa.

In Uganda, a study by Kabagenyi ${ }^{8}$ identified five factors that limit men's participation in reproductive health programmes: (a) perceived side effects of female contraceptive methods that interfere with sexual activity, (b) limited choice of available male contraceptives, including fear and concern about a vasectomy, (c) the perception that reproductive health is a women's domain because of gender norms and traditional, women-centred communication about FP, (d) the preference for large families that are not hindered by prolonged birth spacing, and (e) the fear that women's use of contraceptives may lead to extramarital sex. Thus, men's lack of involvement in FP programmes not only gives them limited exposure but also prevents them from playing a role in fertility control. Indeed, the provision of FP services solely to married women is a barrier to effective fertility control. ${ }^{24}$

The results of DHS in Burkina Faso and several subSaharan countries show that men and women generally have a good grasp of modern contraceptive methods. However, interview results show that misconceptions and prejudices about the side effects of contraceptive methods are major obstacles that men cite when denying their wives access to FP. In Kenya, Harrington et al. ${ }^{25}$ identified the side effects and potential harms of contraceptive methods as limiting factors in men's engagement in FP programmes. Previous studies have also shown that husbands' lack of approval and religious beliefs are determining factors for FP. The education of husbands in many African countries was associated with FP as well. ${ }^{4,26,27}$

Interviews with men revealed that their involvement in FP programmes can be achieved through raising awareness about FP, communicating with their wives about modern contraceptive methods, and providing them with access to reproductive health and FP services. Indeed, sensitising men about FP and contraception is an important element in their involvement. In Burkina Faso, evidence has shown that when men are sensitised, they agree and even encourage women to choose reversible, long-acting contraception. This also helps address barriers such as financial constraints and fear that a disapproving husband might discover an implant insertion site. ${ }^{28}$ Moreover, several studies have shown that providing men with information and involving them in counselling sessions can help them become more supportive of contraceptive use and more aware of the concept of shared decision-making. ${ }^{28,29}$
Men's lack of access to information and services is a barrier to FP as they cannot share responsibility for FP if services and information do not reach them. To encourage men's cooperation, it is important to start by understanding their views rather than relying on their partner's perception of them. Most information, education, and communication (IEC) campaigns on FP are directed only at women, not couples. Some campaigns blame men and present them as irresponsible opponents and an obstacle to accessing FP services. ${ }^{30}$ These types of IEC programmes may prevent men from learning more about FP. There is a need for more positive images and messages about men's roles, as seen in recent IEC programmes. According to this study, most men obtained information about FP from friends, the radio, and newspapers. A few received the same from health workers. This shows that many men do not accompany their partners to the clinic for counselling. ${ }^{8}$

The lack of communication among couples regarding reproductive health and FP issues has long been considered a contributing factor to the unmet need for contraception in SSA. ${ }^{6,25}$ Effective FP requires mutual agreement between spouses. This is only possible if both partners understand the concept of FP and the methods available to prevent unintended pregnancies. ${ }^{24}$ Spousal communication helps couples become aware of each other's views on family size and composition so that a consensus can be reached on contraceptive use. Couples who communicate are more likely to use contraception. Studies support improved communication between spouses about FP because there is mutual understanding and decision-making about fertility and preference. It allows for shared decision-making and more equitable gender roles; discussion among partners is a positive predictor of current contraceptive use. ${ }^{12}$

In Burkina Faso, discussion among couples about FP is one of the most relevant determinants of modern contraceptive practice. ${ }^{11}$ Access to reproductive health and FP services in Burkina Faso and several sub-Saharan countries is limited and often unsuited to men's needs. Findings from the literature reveal that FP information and services in Africa are not targeted at men; rather, they are traditionally presented in the context of maternal and child health. Health workers are sometimes poorly trained to counsel men about safe sex and male contraceptive methods and may communicate negative rumours about them. This focus on women has reinforced the belief that FP is largely a women's issue, with men playing a peripheral role. $^{2}$ 
Several community-based initiatives have been undertaken in Burkina Faso to increase men's access to and involvement in reproductive health and FP programmes. In the Centre-North region of Burkina Faso, the NGO Mangaza Action has set up "Husbands' Schools" to involve men in promoting reproductive health and FP in communities through model husbands and to encourage behavioural change on their part. This initiative has been extended to several regions of Burkina Faso through community structures in villages to promote men's involvement in reproductive health programmes and FP by raising awareness on the use of health services and the adoption of behaviours that value the use of modern contraception.

This study has some limitations that may weaken the results. One of the them is the geographical area. The study covered two administrative regions in Burkina Faso with some of the lowest contraceptive prevalence rates. The results may therefore not be representative at the national level. Moreover, the study is entirely qualitative and exploratory in nature and did not survey a large representative sample. However, these limitations do not call into question the validity of the results.

\section{Conclusion}

This study concludes that the level of men's participation in FP in the country is still low despite interventions by the government and non-governmental organisations. Therefore, additional efforts should be made to improve educational standards, especially for men, and to reorient FP services to make them more accessible to men.

\section{Acknowledgments}

The authors thank the Ministry of Health $(\mathrm{MoH})$ of Burkina Faso for the small grant received through the Health Research Support Fund for data collection.

\section{Funding}

The authors received financial support of "Fonds d'appui à la recherche en santé (FARES)" (Health Research Support Fund) from the Ministry of Health of Burkina Faso for this research.

\section{Disclosure}

Dr Aristide Romaric Bado reports grants from Ministry of Health/Burkina Faso, during the conduct of the study. The authors declare that they have no other potential conflicts of interest for this work.

\section{References}

1. Butto D, Mburu S. Factors associated with male involvement in family planning in West Pokot County, Kenya. Univers $J$ Public Heal. 2015;3:160-168. doi:10.13189/ujph.2015.030404

2. Ijadunola MY, Abiona TC, Ijadunola KT, et al. Male involvement in family planning decision making in Ile-Ife, Osun State, Nigeria. Afr J Reprod Health. 2010;14:43-50.

3. Kan ME, Patel BC. Male involvement in family planning: a KABP study of Agra District Uttar Pradesh. 1997.

4. Ali A, Okud A. Factors affecting unmet need for family planning in Eastern Sudan. BMC Public Health. 2013;13:102. doi:10.1186/14712458-13-102

5. Mekonnen W, Worku A. Determinants of low family planning use and high unmet need in Butajira District, South Central Ethiopia. Reprod Health. 2011;8:1-8. doi:10.1186/1742-4755-8-37

6. Yargawa J, Leonardi-Bee JJ. Male involvement and maternal health outcomes: systematic review and meta-analysis. $J$ Epidemiol Community Health. 2015;69:604-612. doi:10.1136/jech-2014204784

7. Wulifan JK, Bagah DA. Male involvement in family planning in Muslim communities in Wa municipality, Ghana. Res Humanit Soc Sci. 2015;5:86-97.

8. Kabagenyi A, Jennings L, Reid A, Nalwadda G, Ntozi J, Atuyambe L. Barriers to male involvement in contraceptive uptake and reproductive health services: a qualitative study of men and women' $\mathrm{s}$ perceptions in two rural districts in Uganda. Reprod Health. 2014;11:1-9. doi:10.1186/1742-4755-11-21

9. Zoungrana CM, Yacouba Y, Traoré S. Rôle des hommes et des leaders d'opinion dans la promotion de la planification familiale au Burkina Faso: permanence ou changement? Démographie et cultures. 2008;241-253.

10. Andro A. Coopération et conflits entre conjoints en matière de reproduction en Afrique de l'ouest. 2001.

11. Congo Z. Les facteurs de la contraception au Burkina Faso. Analyse à partir des données de l'enquête démographique et de santé de 1999. 2005.

12. Adugnaw B, Sibhatu B, Alemayehu A, et al. Men's knowledge and spousal communication about modern family planning methods in Ethiopia. Afr J Reprod Health. 2011;15:24-32.

13. Onyango MA, Owoko S, Oguttu M. Factors that influence male involvement in sexual and reproductive health in western Kenya: a qualitative study. Afr J Reprod Health. 2010;14:32-42.

14. Ujuju C, Anyanti J, Adebayo SB, et al. Religion, culture and male involvement in the use of the standard days method: evidence from Enugu and Katsina states of Nigeria. Int Nurs Rev. 2011;58:484-490. doi:10.1111/j.1466-7657.2011.00900.x

15. Schuler SR, Hashemi SM, Jenkins AH. Bangladesh's family planning success story: a gender perspective. Int Fam Plan Perspect. 1995;21:132. doi:10.2307/2133319

16. Grady WR, Tanfer K, Billy JOG, Lincoln-Hanson J. Men's perceptions of their roles and responsibilities regarding sex, contraception and childrearing. Fam Plann Perspect. 1996;28:221. doi:10.2307/ 2135841

17. Institut National de la Statistique et de la Démographie - INSD/ Burkina Faso. Tableau de bord social du burkina faso 2017. 2017

18. Konate DL, Sinare T, Seroussi M. Burkina Faso Enquete Demographique et de Sante 1993. Macro International, Incorporated; 1994.

19. Institut National de la Statistique et de la Démographie (INSD) et ORC Macro. Enquête Démographique et de Santé, Burkina Faso 1998-1999. 2000.

20. Institut National de la Statistique et de la Démographie/Burkina Faso; \& ORC Macro. Burkina Faso Enquete Demographique et de Sante 2003. 2004. 
21. Institut National de la Statistique et de la Démographie (INSD) and ICF International. Burkina Faso Enquete demographique et de Sante et à indicateurs multiples (EDSBF-MICS IV) 2010. 2012.

22. Institut Superieur des Sciences de la Population. Results of performance monitoring and accountability 2020, Vague 6, Burkina Faso. 2018.

23. Boeije H. A purposeful approach to the constant comparative method in the analysis of qualitative interviews. Qual Quant. 2002;36:391-409. doi:10.1023/A:1020909529486

24. Pathi S, Rasania SK, Bhalla S, Singh S. Male involvement in family planning practices. Heal Popul Perspect Issues. 2004;27:166-172.

25. Harrington EK, McCoy EE, Drake AL, et al. Engaging men in an mHealth approach to support postpartum family planning among couples in Kenya: a qualitative study. Reprod Health. 2019;16:1-11. doi:10.1186/s12978-019-0669-x

26. Omo-Aghoja LO, Omo-Aghoja VW, Aghoja CO, et al. Factors associated with the knowledge, practice and perceptions of contraception in rural southern. Ghana Med J. 2009;43:115-121.
27. Durowade KA, Omokanye LO, Elegbede OE, et al. Barriers to contraceptive uptake among women of reproductive age in a semi-urban community of Ekiti State, Southwest Nigeria. Ethiop J Health Sci. 2017;27:121-128. doi:10.4314/ejhs.v27i2.4

28. Daniele M, Ganaba R, Sarrassat S, et al. Involving male partners in maternity care in burkina faso: a randomized controlled trial. Bull World Health Organ. 2018;96:450-461. doi:10.2471/BLT.17.206466

29. Berhane A, Biadgilign S, Berhane A, Memiah P. Male involvement in family planning program in Northern Ethiopia: an application of the transtheoretical model. Patient Educ Couns. 2015;98:469-475. doi:10.1016/j.pec.2014.12.012

30. Kamal N. The influence of husbands on contraceptive use by Bangladeshi women. Health Policy Plan. 2000;15:43-51. doi:10.1093/heapol/15.1.43
Open Access Journal of Contraception

\section{Publish your work in this journal}

Open Access Journal of Contraception is an international, peerreviewed, open access, online journal, publishing original research, reports, reviews and commentaries on all areas of contraception. In addition to clinical research, demographics and health-related aspects, the journal welcomes new findings in animal and preclinical

\section{Dovepress}

studies relating to understanding the biological mechanisms and practical development of new contraceptive agents. The manuscript management system is completely online and includes a very quick and fair peer-review system. Visit http://www.dovepress.com/testimonials. php to read real quotes from published authors. 